\title{
23 USING MANDATORY NATIONAL SAFETY AND QUALITY STANDARDS TO EMBED ADVANCE CARE PLANNING IN PRACTICE
}

N Dunbar' 1 J Hill' ${ }^{1}$ Australian Commission On Safety And Quality In Health Care

10.1136/bmjspcare-2012-000250.23

Programs such as Respecting Choices ${ }^{\circledR}$ in the United States and Respecting Patient Choices ${ }^{\circledR}$ in Australia have been developed to address the need for improved advance care planning. Numerous guidelines, policies and pieces of legislation exist to provide guidance on requirements for developing and documenting advance care plans. However the problem of sub-optimal advance care planning persists. A multifactoral approach is needed to address this problem. Within such an approach there may be benefits in looking at the role accreditation can play in driving improvements in advance care planning. Accreditation is part of a comprehensive system to support safe and high quality care. It can verify that actions are being taken, that system data and information are being used to identify problems and develop solutions and that improvements are being achieved. Accreditation processes have been widespread for many years, but have generally not included a requirement to have advance care planning systems in place. In Australia, requirements to have systems for preparing and receiving advance care plans, and for documenting them in the clinical record, are included in new mandatory accreditation 
standards. These National Safety and Quality Health Service Standards provide explicit statements of the expected level of safety and quality of care to be delivered to patients. Hospitals will need to be assessed against these standards from January 2013. This innovative strategy of using mandatory accreditation standards - targeted at a high level - complements more detailed policy and educational programs that already exist. Such an approach will support the implementation of advance care planning programs. 